\title{
A new leader to hold the torch high
}

\author{
Robert B Kalina, Publisher
}

$\mathrm{T}$ he success or failure of an enterprise is dependent on many factors, none of which are more important than the choice of a leader. Peer-review journals are no exception. Publishers, editorial boards, societies and advertisers all have their role in the smooth running of a journal. But it is the true leader - the Editor-in-Chief - who bears the responsibility for the reputation of the journal.

The Canadian Journal of Gastroenterology has been successfully published for 23 years. A key reason for its success is the leadership provided by the various Editors-in-Chief who have served at the helm. It was not only their ability to steer the Journal through challenges but to consistently advance its stature.

The founding Editors-in-Chief, Drs Alan Thomson and Noel Williams struggled to get the Journal off the ground, have it accepted as a legitimate entity and, finally, to have it recognized internationally.

The second leader was Dr Lloyd Sutherland, who, while continuing to heighten the international profile of the Journal, worked tirelessly to solidify support for the Journal from the Canadian Association of Gastroenterology and the Canadian Association for the Study of the Liver here in Canada.

Dr Sutherland passed the leadership to Dr Paul Adams who, similar to his predecessors, threw himself into the battle for the ever important higher Impact Factor and readership, and succeeded beyond anyone's expectations. He also launched new sections in the Journal and collaborated closely with us on our on-line review system put into place during his tenure.

Now, the torch is passed (being an Olympic year) to another very capable individual: Dr Subrata Ghosh, Head of the Division of Gastroenterology at the Teaching, Research and Wellness Centre at the University of Calgary (Alberta). Dr Ghosh differentiated himself from other applicants by having, in addition to stellar scientific qualifications, extensive experience in peerreview journal editing, most notably as an Associate Editor with $\mathrm{Gut}$. He is also a member of the editorial boards of several other important gastroenterology journals.

Because Canada is a relatively small country, publishing a peer-review journal here is no easy task. The number of published pages is always limited by available funds, and there are times when authors of breakthrough studies choose to publish in other journals. However, I have every confidence that Dr Ghosh, like his predecessors, will rise to the occasion and lead The Canadian Journal of Gastroenterology to still greater heights and greater success.

Here's to the future of The Canadian Journal of Gastroenterology under Dr Ghosh. May he hold the torch higher and may it shine brighter for all of us! 


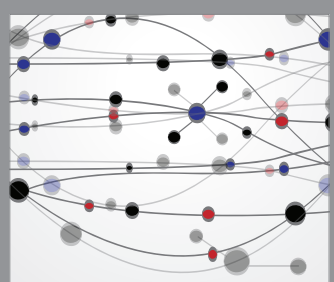

The Scientific World Journal
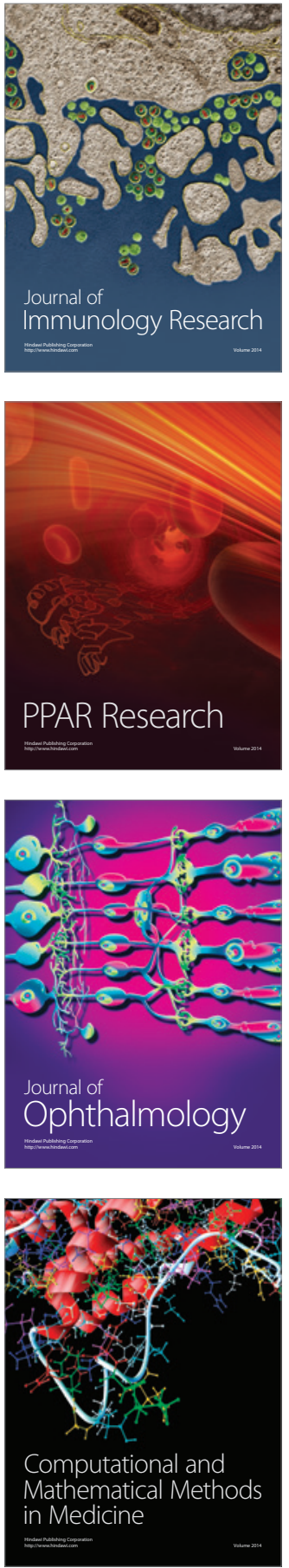

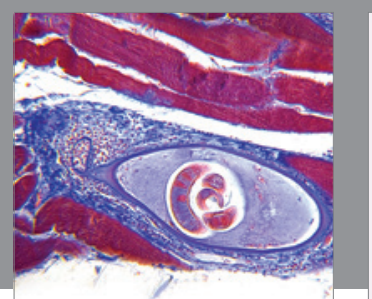

Gastroenterology Research and Practice

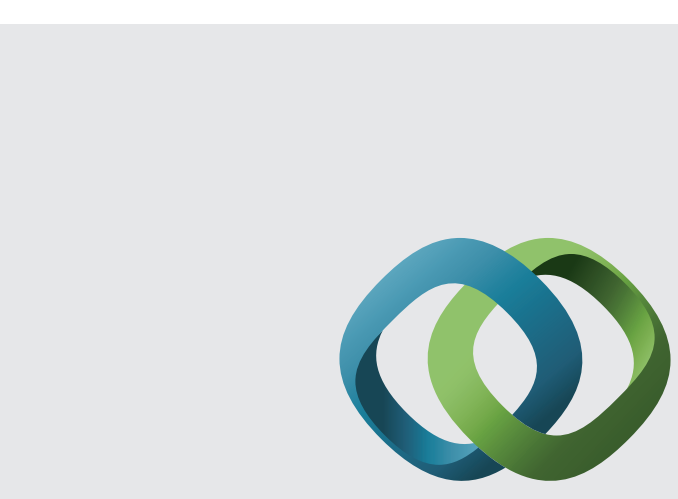

\section{Hindawi}

Submit your manuscripts at

http://www.hindawi.com
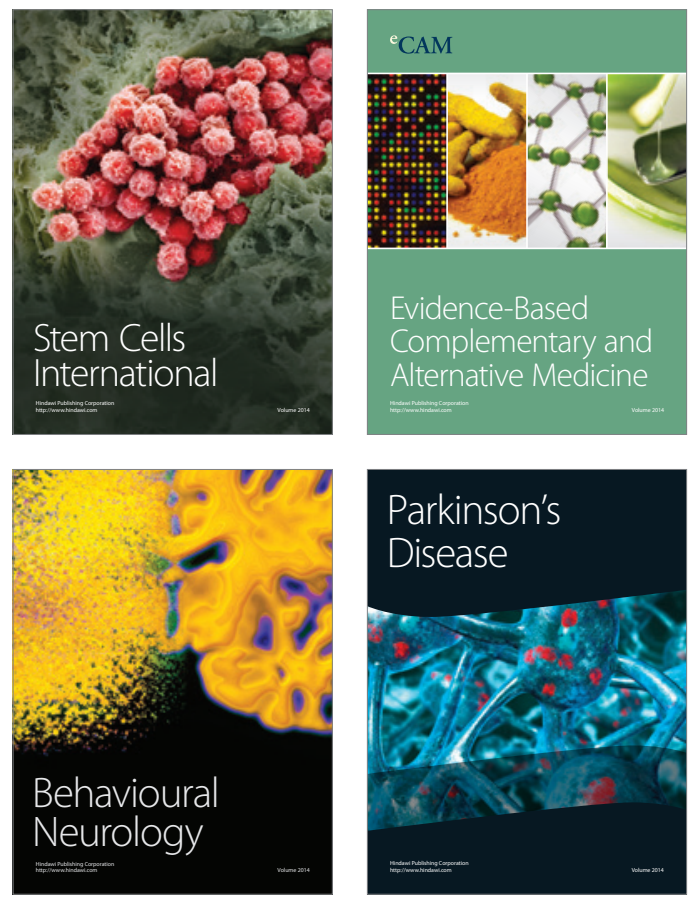
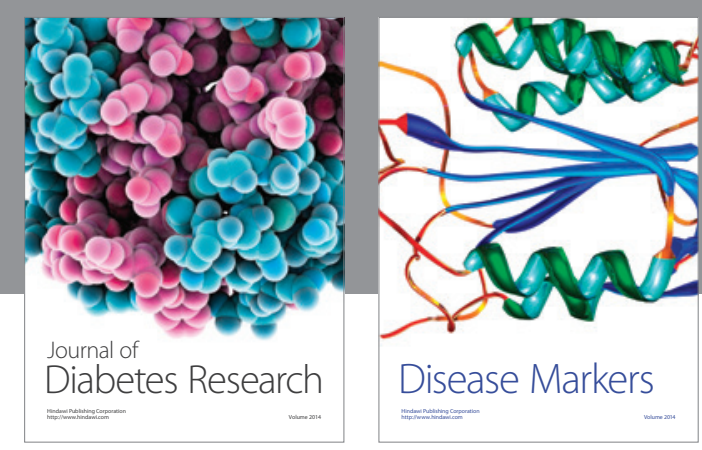

Disease Markers
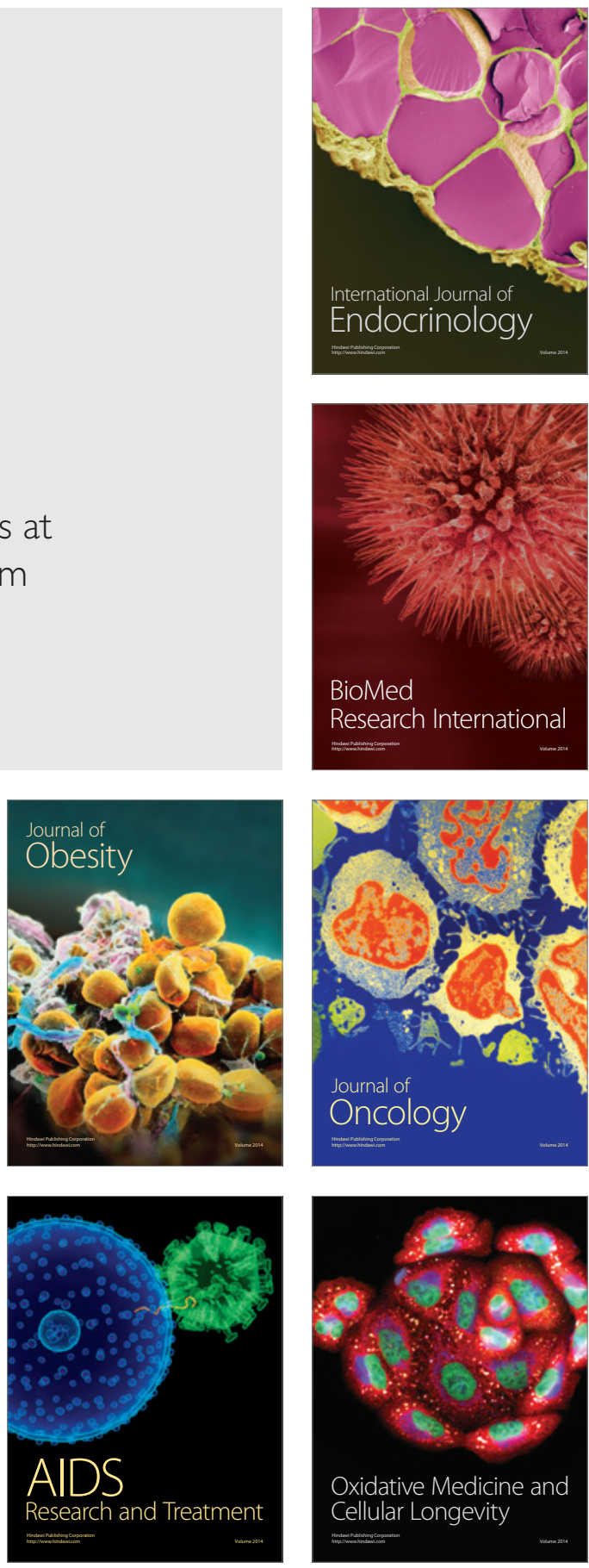